\title{
FRAGMENTAÇÃO DA PAISAGEM NO MUNICÍPIO DE BRAGANÇA PAULISTA-SP
}

\section{FRAGMENTATION OF THE LANDSCAPE IN THE MUNICIPALITY OF BRAGANÇA PAULISTA, SP}

\author{
Lucimara Teixeira ${ }^{1}$ Fernanda Dall'Ara Azevedo² Fabrício Bau Dalmas ${ }^{2}$ Antonio Roberto Saad ${ }^{2}$ Antonio \\ Conceição Paranhos Filho ${ }^{3}$ Marcio Roberto Magalhães de Andrade ${ }^{4}$
}

\section{RESUMO}

A fragmentação e a destruição de habitat são atualmente as maiores causas da redução da biodiversidade. Uma das estratégias de conservação de habitat é a criação de corredores ecológicos que são áreas de conectividade entre fragmentos isolados. Este estudo foi realizado no município de Bragança Paulista, inserido no domínio da Mata Atlântica, região de abrangência do Corredor Mantiqueira na Área de Proteção Ambiental (APA) Piracicaba-Juqueri-Mirim. Os objetivos deste trabalho foram: i - avaliar o isolamento dos remanescentes florestais nativos com base nos parâmetros de paisagem definidos como tamanho, forma, área interior e conectividade; e, ii - identificar áreas potenciais para formação de corredores ecológicos na região de estudo. A metodologia aplicada foi baseada em técnicas de geoprocessamento, em um Sistema de Informações Geográficas e a base de dados utilizada foi composta pelo Inventário Florestal do Estado de São Paulo do Instituto Florestal; cartas topográficas do IBGE, em escala 1:50.000, associada a um plano de informação constituído pelos limites municipais do Instituto Geográfico e Cartográfico do Estado de São Paulo, toda a base em formato vetorial. Os resultados indicaram que a grande maioria dos fragmentos é pequeno, com forma alongada, com baixo índice de área interior e baixa conectividade, o que torna a paisagem de Bragança Paulista e seu entorno bastante fragmentados. Entretanto, vale destacar que esta região ainda contém importantes remanescentes florestais, tanto quando se considera a área de alguns fragmentos, como a conectividade entre eles. Os corredores ecológicos identificados na área de estudo, denominados Corredor Jaguari e Corredor Baronesa-Iguatemi, incluem 74\% de toda a cobertura florestal estudada e, se implantados em Bragança Paulista, poderão contribuir para a formação de um cinturão verde no município com a função de proteção dos recursos hídricos do rio Jaguari e para a manutenção da biodiversidade local e regional.

Palavras-chave: ecologia da paisagem; Mata Atlântica; fragmentos florestais; geoprocessamento.

\begin{abstract}
Habitat fragmentation and destruction are currently the main causes of biodiversity decline. One of the habitat conservation strategies is the creation of ecological corridors that are areas of connectivity between isolated fragments. This study was carried out in the municipality of Bragança Paulista, in the scope of the Atlantic Forest, covering the Mantiqueira Corridor in the Piracicaba-Juqueri-Mirim in the Environmental Protection Area. The objectives of this work were: $\mathrm{i}$ - to evaluate the isolation of native forest remains based on the landscaped parameters defined as size, shape, interior area and connectivity; and, ii - to identify

1 Bióloga, MSc., Universidade São Francisco, Campus de Bragança Paulista, Av. São Francisco de Assis 218, Jd. São José, CEP 12916-900, Bragança Paulista (SP), Brasil. lucimarabio_teixeira@hotmail.com

2 Bióloga, Dra ., Universidade UNG, Praça Teresa Cristina 229, Centro, CEP 07023-070, Guarulhos (SP), Brasil. fdallara.azevedo@gmail.com / fdalmas@prof.ung.br / asaad@ung.br

3 Geólogo, Dr., Centro de Ciências Exatas e Tecnologia, Universidade Federal de Mato Grosso do Sul, Campus Universitário, Caixa Postal, 549, CEP 79060-900, Campo Grande (MS), Brasil. antonio.paranhos@pq.cnpq.br

4 Geólogo, Dr., Coordenadoria Geral de Pesquisa e Desenvolvimento, Centro Nacional de Monitoramento e Alertas de Desastres Naturais, Estrada Dr. Altino Bondensan 500, Distrito de Eugênio de Mello, CEP 12247-016, São José dos Campos (SP), Brasil. magalhaes_andrade@ig.com.br
\end{abstract}

Recebido para publicação em 14/09/2016 e aceito em 31/05/2017

Ci. Fl., v. 28, n. 3, jul. - set., 2018 
potential areas for ecological corridors formation in the study area. The applied methodology was based in a Geographic Information System and the database used was composed by the Forest Inventory of the State of São Paulo, developed by Forest Institute; topographic maps of Instituto Brasileiro de Geografia e Eestatística, in scale of 1:50,000, associated with an shapefile data constituted by the municipal boundaries of the Instituto Geográfico e Cartográfico do Estado de São Paulo, all based on vector format. The results indicated that the great majority of the fragments are small, elongated, with low index of interior area and low connectivity, which makes the landscape of Bragança Paulista and its surroundings quite fragmented. However, it should be noted that this region still contains important forest remnants, both when considering the area of some fragments and the connectivity between them. The ecological corridors identified in the study area, known as the Jaguari Corridor and Baronesa-Iguatemi Corridor, include $74 \%$ of all forest cover studied and, if implemented in Bragança Paulista city, can contribute to the formation of a green belt in the municipality with the function of Protect the Jaguari River's water resources and for the maintenance the local and regional biodiversity.

Keywords: landscape ecology; Atlantic Forest; forest fragments; geoprocessing.

\section{INTRODUÇÃO}

Em 1500, com a chegada dos portugueses, iniciou-se o primeiro ciclo de exploração do pau-brasil na Mata Atlântica. Nesta época, este bioma representava 15\% do continente brasileiro e desenvolvia-se por quase toda a costa atlântica. Este sistema apresentava uma faixa de largura variável e chegava na região sudeste, avançava rumo oeste, atravessando as atuais fronteiras com o Paraguai e a Argentina, onde se situam as Cataratas do Iguaçu. Nessa área, desenvolveram-se os ciclos econômicos da cana-de-açúcar, do algodão e do café, seguidos, já nos séculos XIX e XX, por intensos processos de urbanização e expansão agrícola (RESERVA DA BIOSFERA DA MATA ATLÂNTICA, 2009).

De acordo com Atlas dos Remanescentes Florestais da Mata Atlântica (período 2008-2010), na região sudeste, o Estado do Espírito Santo tem 11,07\% da cobertura vegetal deste bioma; Minas Gerais com 10,04\%; Rio de Janeiro, 19,61\%; e São Paulo com 15,78\% de cobertura florestal. No Estado de São Paulo, os remanescentes de vegetação nativa estão concentrados na região costeira, nas serras do Mar, da Bocaína e da Mantiqueira, nos vales do Ribeira e do Paraíba, e no Cinturão Verde de São Paulo (FUNDAÇÃO SOS MATA ATLÂNTICA; INSTITUTO NACIONAL DE PESQUISAS ESPACIAIS, 2011).

Esta fragmentação de habitat é responsável pela redução de $13 \%$ a $75 \%$ da biodiversidade e resulta em prejuízos a processos ecossistêmicos fundamentais, como a ciclagem de nutrientes e diminuição da biomassa arbórea, perda da diversidade, devido, principalmente, à perda e isolamento de habitat entre outros (CERQUEIRA et al., 2003; RAMBALDI; OLIVEIRA, 2003; HADDAD et al., 2015). Para conter essas alterações, a implantação de corredores ecológicos é uma das estratégias de conservação na tentativa de restabelecer conectividade na paisagem fragmentada. Além da presença dos corredores ecológicos, outros fatores como largura, qualidade dos corredores, capacidade de dispersão das espécies e interações ecológicas (positivas e negativas) irão modular o efeito destes na diversidade de espécies (CHRISTIE; KNOWLES, 2015).

A definição de indicadores ambientais para a seleção de áreas que possam servir como corredor ecológico é uma estratégia importante para a conservação de um sistema tão fragmentado como a Mata Atlântica. Dentre estes indicadores, estão os parâmetros de estrutura da paisagem que avaliam a fragmentação de um ambiente como tamanho, forma, área interior do fragmento, conectividade, dispersão (LOCH et al., 2013; WANG; BLANCHET; KOPER, 2014). A qualidade dos fragmentos pode ser avaliada utilizando diferentes métricas. Uma delas é a associação de dois fatores: tamanho e circularidade (RANTA et al., 1998). Dessa forma, fragmentos com áreas maiores e menos recortados são preferíveis, pois apresentam menor proporção de borda-área. Uma outra forma de avaliar a qualidade dos fragmentos é o tamanho da área interior, que também é um indicador de efeito de borda (MCGARIGAL, 2002). Outra métrica importante é a conectividade. Fragmentos com maior conectividade entre si indicam ambientes com maior potencial para a manutenção de um número maior de espécies nativas, o que aumenta a probabilidade de êxito na conservação de espécies da flora e fauna (METZGER et al., 2008). O efeito da fragmentação de habitat na ocorrência das espécies irá depender do tipo de habitat, da qualidade dos mesmos e do uso da 
matriz adjacente a esses fragmentos (BENNET; SAUNDERS, 2010)

O presente trabalho avaliou as condições de fragmentação dos remanescentes florestais nativos do município de Bragança Paulista - SP, utilizando-se as seguintes métricas de análise da paisagem: tamanho, forma, área interior e conectividade. A partir da estimativa destas métricas, foram identificadas áreas potenciais para a criação de corredores ecológicos, com o intuito de contribuir com o poder público no estabelecimento de ações de conservação das áreas de vegetação nativa remanescente, de recursos hídricos e da biodiversidade na região de estudo.

\section{MATERIAL E MÉTODO}

\section{Área de estudo}

A área de estudo compreende o território do município de Bragança Paulista - SP, acrescida de uma zona no entorno de $2 \mathrm{~km}$, envolvendo vários fragmentos florestais nativos adjacentes. Estão inseridos na área de estudo parte dos municípios limítrofes, sendo: ao norte Pinhalzinho e Pedra Bela; ao sul Atibaia; ao leste Piracaia e Vargem, ao oeste Tuiuti, Morungaba, Itatiba e Jarinu, totalizando uma área de 75.952 hectares (Figura 1).

A região encontra-se no Planalto Atlântico, especificamente no compartimento denominado de Planalto de Jundiaí com predomínio do relevo de morros com serras restritas, localizado a oeste do extremo sudoeste da Serra da Mantiqueira (PONÇANO et al., 1981). A cobertura pedológica é dominada por argissolos e latossolos vermelho-amarelados, podendo ser encontrado cambissolos, litossolos e solos hidromórficos (GAMEIRO; SUGUIO, 2008). Conforme classificação de Köppen, o clima da área de estudo é do tipo Cwa, clima tropical de altitude, com chuvas no verão e seca no inverno, com a temperatura média do mês mais quente superior a $22^{\circ} \mathrm{C}$ (SÃO PAULO, 2009).

Segundo o Inventário Florestal da Vegetação Natural do Estado de São Paulo, o município de Bragança Paulista possui uma vegetação nativa, que corresponde a 5,7\% da superfície do Estado de São Paulo (KRONKA et al., 2005).

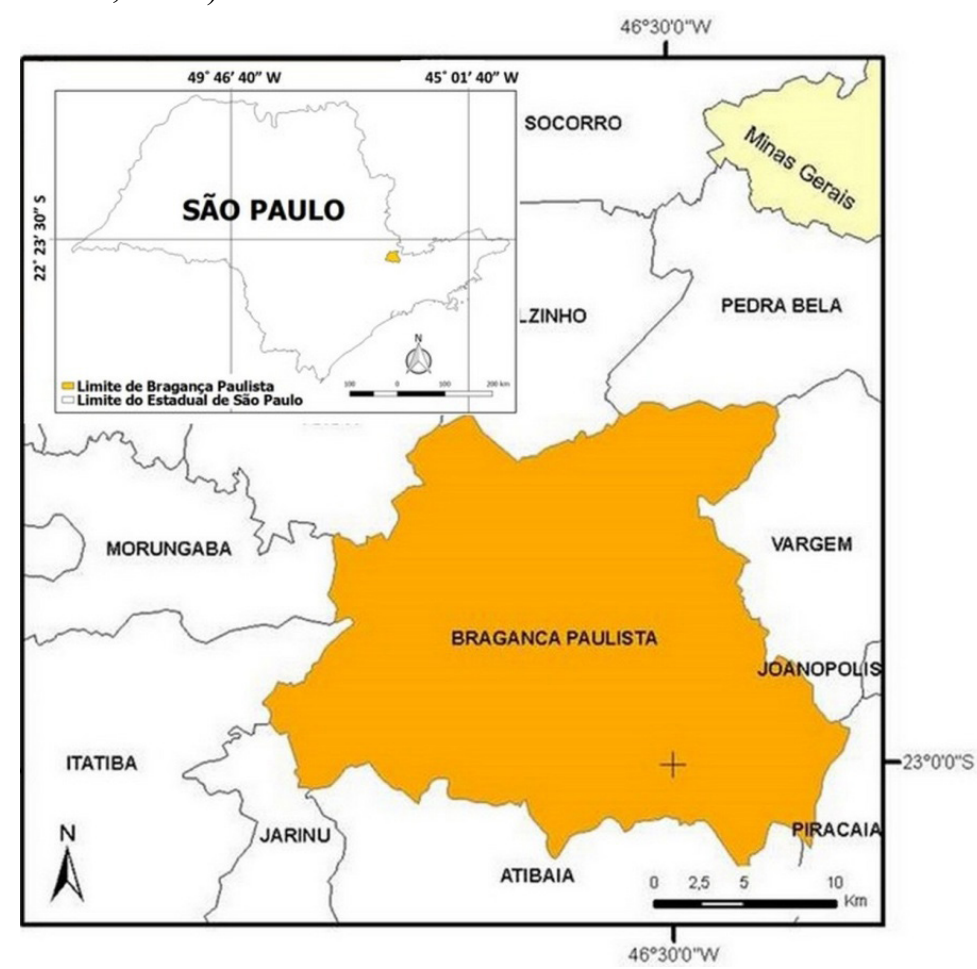

FIGURA 1: Localização geográfica do município de Bragança Paulista-SP.

FIGURE 1: Geographical location of the Bragança Paulista (SP) municipality. 


\section{Mapeamento}

O presente trabalho foi implementado em duas etapas: a primeira consistiu em procedimentos de compilação e montagem de um banco de dados espaciais, em ambiente de um Sistema de Informações Geográficas (SIG). A principal base de dados, na primeira etapa, foi obtida por meio do Inventário Florestal do Estado de São Paulo do Instituto Florestal. Na segunda etapa, foram implementadas operações de Geoprocessamento no SIG.

A base cartográfica foi adquirida na forma de uma base digital contínua das cartas topográficas do IBGE, em escala 1:50.000 (IBGE, 2015), associada a um plano de informação constituído pelos limites municipais do Instituto Geográfico e Cartográfico do Estado de São Paulo (IGC), ambos em formato vetorial (Projeção UTM, datum 23/S).

O geoprocessamento foi implementado com software ArcGIS®, versão 9.3 (ENVIRONMENTAL SYSTEMS RESEARCH INSTITUTE, 2009), modalidade ARCINFO com extensões, disponibilizado pelo Laboratório de Geoprocessamento do Programa de Mestrado em Análise Geoambiental da Universidade Guarulhos. A base temática digital foi formada pelos seguintes planos de informação ou camadas:

a) Fragmentos florestais do IFESP de 2008-2009 em formato vetorial (shape), compatível com a escala 1: 25.000 (INSTITUTO FLORESTAL, 2009);

b) Uso do solo da Reserva da Biosfera do Cinturão Verde (RBCV) de 2006 em formato vetorial (shapefile), compatível com a escala 1:50.000 (OLIVEIRA, 2005).

Os procedimentos analíticos de geoprocessamento consistiram basicamente em operações de buffer, selecionamento (query) por atributos e localização, classificações utilizando a calculadora de campo, avaliações estatísticas como somatório, média e desvio padrão, e outras relacionadas à confecção de "layouts" e produção de mapas. Assim, foi possível estimar as métricas necessárias quanto aos parâmetros: tamanho, forma e conectividade dos fragmentos florestais, abrangendo o território e uma faixa num raio de $2 \mathrm{~km}$ além dos limites administrativos de Bragança Paulista.

Os procedimentos para a análise do tamanho dos fragmentos florestais foram feitos utilizando o módulo XTools do ArcGIS ${ }^{\circledR}$ (versão 9.3), que gerou automaticamente as áreas (superfície) e perímetro de cada polígono ou fragmento mapeado. Os resultados foram avaliados diretamente na tabela de atributos, na qual foi possível efetuar as estatísticas do parâmetro tamanho.

\section{Tamanho dos fragmentos florestais}

Os fragmentos florestais foram divididos em 3 classes de tamanho, conforme apresentado na Tabela 1. A classificação adotada foi baseada em Ribeiro et al. (2009), com os fragmentos maiores que 100 ha condensado em uma única classe.

TABELA 1: Classificação adotada com relação ao tamanho dos fragmentos florestais na região de Bragança Paulista. TABLE 1: Classification adopted of forest fragment size in Bragança Paulista and region.

\begin{tabular}{cc}
\hline $\begin{array}{c}\text { Tamanho dos } \\
\text { fragmentos }\end{array}$ & $\begin{array}{c}\text { Intervalos de classe da área dos } \\
\text { fragmentos (ha) }\end{array}$ \\
\hline Pequeno & $<50$ \\
Médio & $\geq 50 \mathrm{E}<100$ \\
Grande & $\geq 100$ \\
\hline
\end{tabular}

\section{Forma dos fragmentos florestais}

Baseados na teoria de biogeografia de ilhas de MacArthur e Wilson (1967), quanto menor a relação perímetro/área de um determinado remanescente de floresta melhor é para a conservação, pois os fragmentos circulares apresentam a razão borda/interior baixa, enquanto fragmentos alongados e irregulares apresentam esta razão alta (DITT, 2002). 
A análise da forma dos fragmentos florestais foi conduzida a partir da estimativa do Índice de Circularidade (CHATURVEDI, 1926):

$$
I c=\frac{40000 \pi A}{P^{2}}
$$

Em que: $\mathrm{IC}=$ índice de circularidade; $\mathrm{A}=$ área do fragmento, em ha; e $\mathrm{P}=$ perímetro do fragmento, em metros.

O índice de circularidade é adimensional e varia de 0 a 1 , sendo que haverá tendência à forma arredondada quando o valor for mais próximo de 1 . À medida que o índice se distancia de 1 , tem-se um fragmento alongado (GREGGIO; PISSARRA; RODRIGUES, 2009). O critério para a classificação da forma considerou a subdivisão do índice de circularidade em três classes de forma, baseando-se em Ditt (2002) e apresentadas na Tabela 2.

TABELA 2: Forma dos fragmentos florestais, baseada no índice de circularidade.

TABLE 2: Shape of fragment forest based on the circularity index.

\begin{tabular}{cc}
\hline Classificação da forma & $\begin{array}{c}\text { Intervalos de valores do índice de } \\
\text { circularidade }\end{array}$ \\
\hline Compacta/ Circular & $>0,66$ \\
Intermediária & $>0,33$ circularidade $\leq 0,66$ \\
Alongada/Irregular & $\leq 0,33$ \\
\hline
\end{tabular}

\section{Área interior dos fragmentos florestais}

Para a avaliação da área interior dos fragmentos de vegetação nativa remanescentes na área de estudo, utilizou-se o índice de área interior. Este índice consiste, na razão entre a área interna e a área total do fragmento, em outras palavras, no percentil que uma determinada área interna representa em relação ao fragmento como um todo (METZGER et al., 2008). Segundo estes autores, ao efetuar a avaliação dos remanescentes naturais no Estado de São Paulo, com base em uma análise puramente estrutural, propuseram a adoção de uma faixa de borda de 50 metros indistintamente, sendo esta distância também adotada neste trabalho. No presente estudo, o critério para a definição de classes de área interior dos fragmentos considerou a subdivisão do índice de área interior em 5 classes de área interior, conforme apresentado na Tabela 3.

TABELA 3: Área interior dos fragmentos florestais na região de Bragança Paulista.

TABLE 3: Inside area of fragment forest in Bragança Paulista and region.

\begin{tabular}{cc}
\hline $\begin{array}{c}\text { Área interior } \\
\text { dos fragmentos }\end{array}$ & $\begin{array}{c}\text { Intervalo de classe para o índice de } \\
\text { área interior }(\%)\end{array}$ \\
\hline Alto & área interior $>60$ \\
Médio & $>40$ área interior $\leq 60$ \\
Baixo & $>20$ área interior $\leq 40$ \\
Muito baixo & $>0$ área interior $\leq 20$ \\
Irrelevante & $<0$ \\
\hline
\end{tabular}




\section{Conectividade dos fragmentos florestais}

A análise da conectividade foi conduzida a partir da estimativa da proximidade entre os fragmentos florestais, com base no conceito de "stepping stone" apresentado por Bennett (2003). Desta forma, partindose das áreas-núcleo, foram efetuadas operações de buffer com determinadas distâncias que permitiram classificar os fragmentos de acordo com Durigan et al. (2009), conforme Tabela 4.

TABELA 4: Definição das classes de conectividade dos fragmentos florestais nativos na região de Bragança Paulista. TABLE 4: Classification adopted about connectivity of forest fragments in Bragança Paulista region.

\begin{tabular}{cc}
\hline $\begin{array}{c}\text { Conectividade dos } \\
\text { fragmentos }\end{array}$ & $\begin{array}{c}\text { Intervalo de classe para distância } \\
\text { entre fragmentos área- núcleo }(\mathrm{m})\end{array}$ \\
\hline Alta & $\leq 100$ \\
Média & $>100$ conectividade $\leq 200$ \\
Baixa & $>200$ \\
\hline
\end{tabular}

\section{Avaliação dos corredores ecológicos}

O critério para identificação de fragmentos conectados por Áreas de Preservação Permanente (APPs) considerou apenas as Áreas de Proteção Permanente (APP) relacionadas às faixas marginais de qualquer curso d'água natural perene e intermitente, conforme descrito na Lei Federal $\mathrm{n}^{\mathrm{o}} 12.651$ (BRASIL, 2012). Portanto, foram considerados os fragmentos florestais que estão em uma faixa de 30 metros ao redor dos cursos d'água e de 50 metros com relação aos espelhos d'água. Não foram consideradas as nascentes por não haver cadastro destas. Cabe destacar que essa análise utilizou uma base cartográfica do IBGE na escala 1: 50.000 (IBGE, 2015).

Os critérios utilizados no método de avaliação da conectividade florestal foram os seguintes:

I - Foram consideradas como área-domínio as áreas resultantes da operação de buffer;

II - Os fragmentos foram classificados como: Áreas Conectadas quando apresentaram superfície resultante de um buffer de 30 metros maior ou igual a 100 ha; Áreas Mediamente Conectadas quando apresentaram superfície resultante de um buffer de 300 metros maior ou igual a 100 ha. Desconectados quando não atenderam às condições anteriores.

Para a identificação dos corredores ecológicos, o critério adotado foi o reconhecimento das áreas contíguas que agregam uma quantidade significativa de fragmentos florestais, com conectividade alta ou média e com a presença de Áreas-Núcleo. Para essa análise foram consideradas Áreas-domínio igual ou maior que 1.000 ha, a partir de buffers de 300 metros, e a associação com Áreas-Núcleo.

\section{RESULTADOS E DISCUSSÃO}

Os resultados deste estudo indicam que, em relação ao somatório das áreas dos fragmentos, $53 \%$ dos fragmentos de vegetação nativa são considerados pequenos. A média e o desvio padrão em relação ao tamanho dos fragmentos registrada no estudo foi de $7 \pm 8,8 \mathrm{DP}$ ha. Os fragmentos menores do que 100 ha somam 843 , ou seja, 70,4\% da cobertura florestal da área é composta por esses fragmentos, o que corresponde a 7.500,2 ha da cobertura florestal da área de estudo. Dezoito fragmentos foram considerados grandes (área igual ou maior que $100 \mathrm{ha}$ ), representando 2,1\% dos 861 fragmentos analisados. A somatória deles resultou numa área total de $3.157,4$ ha, que corresponde a $29,6 \%$ da cobertura florestal estudada (Tabela 5).

O número de fragmentos indica o grau de fragmentação da paisagem estudada. Um maior número de fragmentos pequenos indica que a paisagem está mais fragmentada (MCGARIGAL, 2002). A partir da análise da fragmentação florestal nativa de Bragança Paulista, observou-se que embora a paisagem esteja bastante fragmentada, ainda contém importantes remanescentes florestais nativos. Como consequência da redução das áreas de florestas nativas, tem-se o aumento da fragmentação de habitat que pode levar 
à diminuição exponencial no número de espécies de fauna e flora (FAHRIG, 2003).

$\mathrm{Na}$ área estudada, 27 fragmentos apresentaram áreas maiores de 50 ha e 18 fragmentos apresentaram áreas maiores do que 100 ha, o que indica que a região estudada ainda apresenta importantes remanescentes florestais em relação ao tamanho. Porém, a grande maioria dos fragmentos foram classificados como pequenos (816 fragmentos menores que $50 \mathrm{ha}$ ), o que é comum para as paisagens de Floresta Atlântica (RANTA, 1998; ZANELLA et al., 2012; SOUZA et al., 2014). Em estudo realizado nas Áreas de proteção ambiental do Município de Coqueiral (Estado de Minas Gerais), Souza et al. (2014) concluíram que 48\% dos fragmentos estudados tinham áreas menores que 10 ha. Estes fragmentos menores como ocorrem na região estudada e no município de Coqueiral, são importantes na paisagem, uma vez que podem funcionar como pontes entre fragmentos maiores, o que facilitaria, para algumas espécies, o fluxo entre os fragmentos, que é corroborado por Ribeiro et al. (2009) e Calegari et al. (2010).

TABELA 5: Classificação e estatística dos parâmetros analisados.

TABLE 5: Classification and Statistics of the parameters analyzed.

\begin{tabular}{|c|c|c|c|c|c|c|c|c|c|}
\hline \multirow{2}{*}{ Parâmetro } & \multirow{2}{*}{ Categoria } & \multicolumn{2}{|c|}{ Fragmento } & \multicolumn{4}{|c|}{ Área (ha) } & \multicolumn{2}{|c|}{$\begin{array}{c}\Sigma \text { Total das áreas } \\
\text { dos fragmentos }\end{array}$} \\
\hline & & $\mathrm{N}$ & $\%$ & $\begin{array}{c}\text { Menor } \\
\text { fragmento } \mathrm{t}\end{array}$ & $\begin{array}{l}\text { Maior } \\
\text { fragmento }\end{array}$ & Média & $\begin{array}{l}\text { Desvio } \\
\text { padrão }\end{array}$ & Hectare & $\%$ \\
\hline \multirow{3}{*}{ Tamanho } & Grande & 18 & 2,1 & 101,6 & 363 & 175,4 & 78,4 & $3.157,40$ & 29,6 \\
\hline & Médio & 27 & 3,1 & 52,1 & 91,7 & 67,5 & 12 & $1.823,60$ & 17 \\
\hline & Pequeno & 816 & 94,8 & 0,01 & 49,9 & 7 & 8,8 & $5.676,60$ & 53,26 \\
\hline \multirow{3}{*}{ Forma } & Comp. & 215 & 25 & 0,01 & 28,5 & 2,9 & 4,2 & 631,3 & 5,92 \\
\hline & Int. & 359 & 41,7 & 0,3 & 106,7 & 5,7 & 8,3 & $2.055,10$ & 19,28 \\
\hline & $\begin{array}{l}\text { Alongada/ } \\
\text { Irregular }\end{array}$ & 287 & 33,3 & 0,8 & 363 & 27,8 & 46,9 & $7.971,30$ & 74,79 \\
\hline \multirow{5}{*}{ Área Interior } & Alta & 11 & 1,3 & 26,3 & 363 & 149,1 & 110,9 & $1.640,20$ & 15,39 \\
\hline & Média & 88 & 10,2 & 8,8 & 286 & 48,1 & 49,4 & $4.233,90$ & 39,73 \\
\hline & Baixa & 130 & 15,1 & 4,5 & 91,7 & 18,6 & 15,7 & $2.417,70$ & 22,69 \\
\hline & MB & 350 & 40,6 & 1,1 & 37 & 5,6 & 4,5 & $1.953,70$ & 18,33 \\
\hline & Irrelevante & 282 & 32,8 & 0,01 & 6,9 & 1,5 & 1,1 & 412,1 & 3,87 \\
\hline \multirow{4}{*}{ Conectividade } & $\begin{array}{l}\text { Áreas- } \\
\text { Núcleo }\end{array}$ & 18 & 2,1 & 101,6 & 363 & 175,4 & 78,4 & $3.157,40$ & 29,63 \\
\hline & Alta & 46 & 5,3 & 0,05 & 85,2 & 14,3 & 17,8 & 659,5 & 6,19 \\
\hline & Média & 71 & 8,3 & 0,2 & 91,7 & 12,5 & 19,4 & 886 & 8,31 \\
\hline & Baixa & 726 & 84,3 & 0,01 & 87,5 & 8,2 & 12,8 & $5.954,80$ & 55,87 \\
\hline
\end{tabular}

Em que: $\mathrm{N}=$ o número de fragmentos, Comp. = Compacta, Int. = Intermediária, MB = Muito Baixa.

O Mapa dos Fragmentos Florestais de Bragança Paulista (Figura 2) apresenta a predominância tanto em número, quanto em área de fragmentos com circularidade intermediária e alongada (75\%). Apenas $25 \%$ dos fragmentos apresentam circularidade compacta (Tabela 5). Estes resultados corroboram estudos anteriores em que a forma irregular registrou um predomínio em relação às formas circulares (SOUZA et al., 2014). Fragmentos maiores apresentaram forma irregular, enquanto que os fragmentos classificados como compactos foram fragmentos pequenos. Não foi possível observar, no estudo, a ocorrência de fragmentos de tamanho médio ou grande classificados com circularidade intermediária ou compacta. Ou seja, os melhores fragmentos com relação à forma são pequenos. Estes resultados já foram observados 
anteriormente por Calegari et al. (2010), e sugerem uma relação de "custo-benefício" entre o tamanho do fragmento e sua circularidade. Ou seja, fragmentos maiores, apesar de baixo índice de circularidade, devido a sua área, tendem a manter maior diversidade de espécies. Porém, se o índice de circularidade for muito baixo, esses fragmentos terão grande influência do efeito de borda, mesmo que ocupe uma área maior. Dessa forma, o tamanho e a conectividade podem ser mais importantes do que a forma propriamente dita (DITT, 2002), porque áreas maiores e mais conectadas tendem a formar um mosaico na paisagem. Áreas maiores são importantes na manutenção das espécies, e a conectividade permite uma maior dispersão entre elas. Adicionalmente, os remanescentes mapeados, neste estudo, exercem função importante na manutenção dos recursos hídricos da região, uma vez que grande parte se encontra conectados a APP. E, por estarem associados a cursos d'água natural, tendem ter índice de circularidade intermediário e alongado.

Corroborando a métrica forma, o número de fragmentos com área interior muito baixa ou irrelevante é expressivo e compõem $73,4 \%$ dos fragmentos analisados. Os fragmentos florestais classificados com índice de área interior "alto" são poucos e representam apenas 1,3\% dos fragmentos estudados, somando uma área de 1.640,2 hectares (15,4\% da cobertura florestal estudada). O menor fragmento com área interior alta têm 26,3 ha e o maior 363 ha. Estes fragmentos são importantes porque podem ser considerados fragmentos com melhor qualidade para abrigar a biodiversidade local. Dessa forma, a área interior é um indicador mais adequado para avaliar a qualidade de um fragmento do que a área total, pois evidencia a área do fragmento que sofre pouca ou nenhuma influência do efeito de borda (MCGARIGAL, 2002). A maioria dos fragmentos estudados, $73,4 \%$, apresenta área interior muito baixa ou irrelevante, indicando um alto grau de comprometimento dos fragmentos remanescentes na área estudada.

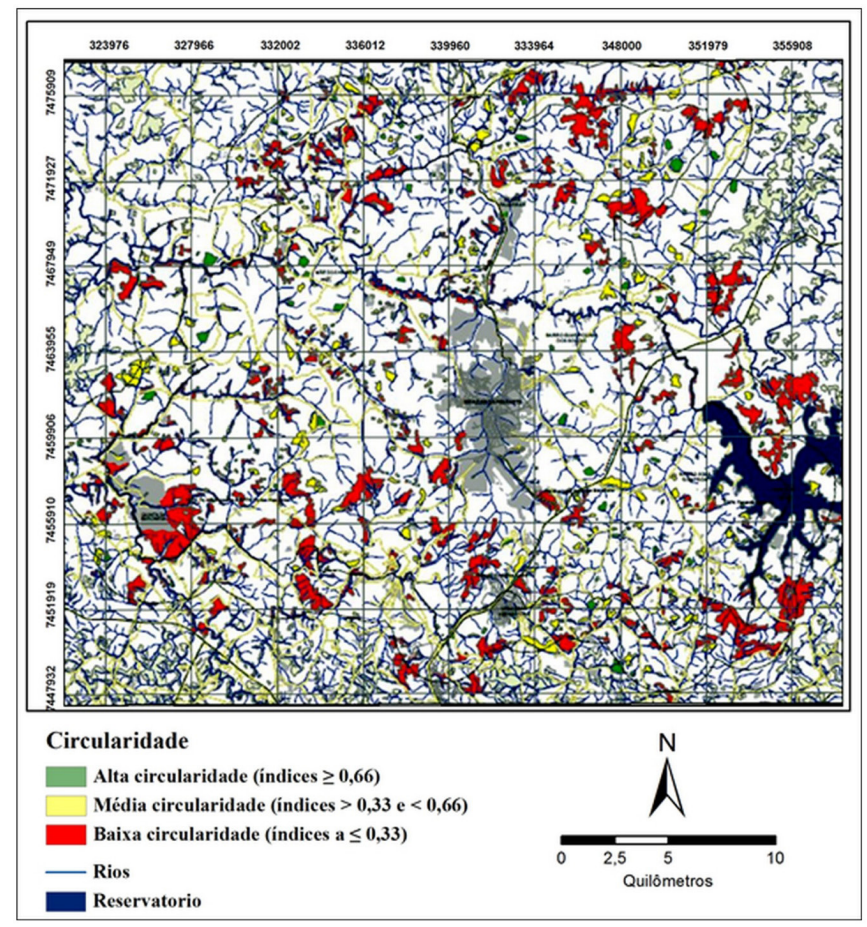

FIGURA 2: Mapa dos Fragmentos Florestais de Bragança Paulista, classificados com base na forma. FIGURE 2: Map of Forest Fragments in Braganca Paulista, based on shape classification.

A análise da conectividade revelou que um total de 18 fragmentos foram considerados áreas-núcleo, 46 fragmentos foram considerados com conectividade alta e 726 com conectividade baixa (Tabela 5). O resultado gráfico dessa análise é apresentado no Mapa dos Fragmentos Florestais de Bragança Paulista classificados com base na Conectividade, apresentado na Figura 3. Os fragmentos analisados apresentaram baixa conectividade, ou seja, a maioria dos fragmentos estava a uma distância maior do que $200 \mathrm{~m}$ das Áreas-Núcleo. Os resultados encontrados na literatura são bem variados. Em alguns casos, os fragmentos estão relativamente próximos, isto é, a uma distância média de 38,9 m um dos outros (SOUZA et al., 2014); em outros casos, esta distância pode chegar a 244,5 m (CALEGARI et al., 2010). Não há um consenso sobre 
a partir de qual distância o fluxo de organismos é afetado, mesmo porque isto irá depender da espécie-alvo a ser estudada (CHRISTIE; KNOWLES, 2015). Entretanto, fragmentos com baixa conectividade, como os encontrados na área de estudo, prejudicam a movimentação de espécies entre os fragmentos, diminuindo o fluxo gênico, a colonização, bem como a permanência das espécies (ALMEIDA, 2008).

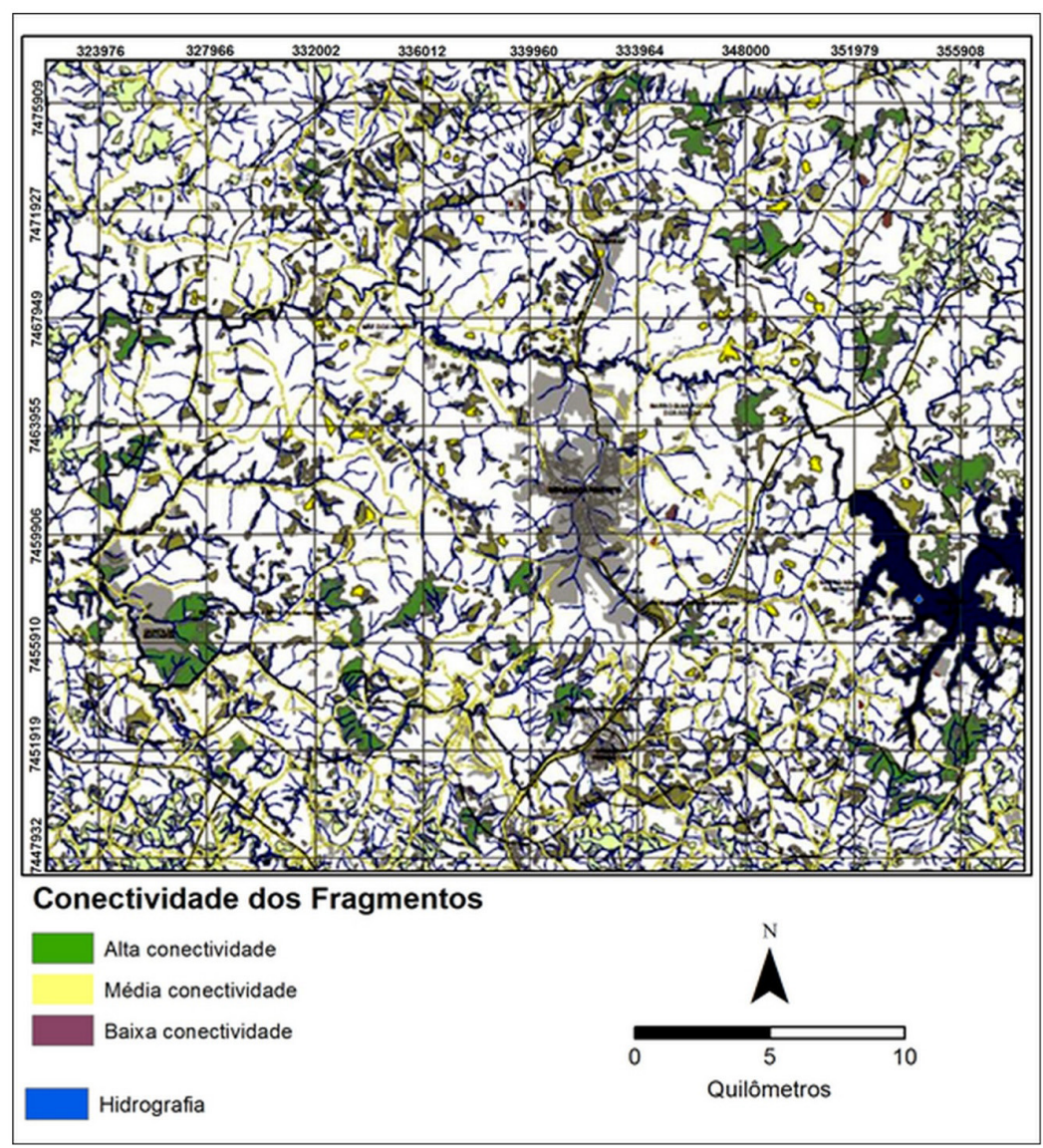

FIGURA 3: Mapa dos Fragmentos Florestais de Bragança Paulista, classificados de acordo com as classes de conectividade.

FIGURE 3: Map of forest fragments in Braganca Paulista, classified according to the connectivity classes.

\section{Avaliação dos corredores ecológicos}

Foram identificados 595 fragmentos de remanescentes florestais nativos conectados por APP, sendo que 400 destes estão diretamente relacionados ao território de Bragança Paulista. A somatória destes perfaz uma superfície total de $9.836,6$ hectares, ou seja, aproximadamente $92,9 \%$ de toda a cobertura florestal estudada. Os parâmetros utilizados para a identificação dos corredores ecológicos mostram duas regiões com alta probabilidade para a implementação de corredores ecológicos (Figura 4).

O Corredor Jaguari tem o seu desenvolvimento notadamente a noroeste do Reservatório do Jaguari, em uma extensão de $24,5 \mathrm{~km}$, localizado a nordeste do centro de Bragança Paulista, com uma superfície total de cerca de 16,4 mil hectares. Compõe uma faixa com direção aproximada sudeste-noroeste que se desenvolve desde áreas próximas ao reservatório do Jaguari. Este corredor envolve um total de 115 fragmentos florestais, dos quais sete são áreas-núcleo, três delas contidas no território de Bragança Paulista, seis são fragmentos de tamanho médio e 102 são pequenos. Em relação à conectividade, $41 \%$ dos fragmentos apresentam conectividade média ou alta. A superfície florestal contida corresponde a $26,5 \%$ de toda a cobertura estudada. O corredor apresenta um índice de 17,2\% de cobertura florestal (Figura 4).

O Corredor Baronesa-Iguatemi está localizado no flanco sul da área de estudo, no entorno da divisa com o município de Atibaia, em uma extensão aproximada de $36 \mathrm{~km}$, com uma superfície de 21,7 mil 
hectares. Envolve um total de 10 áreas-núcleo, formando um faixa com direção aproximada leste-oeste (Figura 4). Esse corredor se forma desde o município de Piracaia, até as divisas com os municípios de Jarinu e Itatiba, todos no Estado de São Paulo (Figura 1). A formação do Corredor Baronesa-Iguatemi envolve um total de 356 fragmentos florestais, dos quais 12 são fragmentos de tamanho médio e 333 são pequenos. Do total de fragmentos identificados, $27 \%$ deles apresentam conectividade média ou alta. Assim, recomendase uma atenção especial no eixo do Corredor Baronesa-Iguatemi, pois nele ocorrem 8 áreas-núcleo. Trata-se de uma região de crescente expansão imobiliária urbana, com terrenos próximos ao reservatório do Jaguari a sudeste, sendo, portanto, uma área de convergência com Corredor Jaguari.

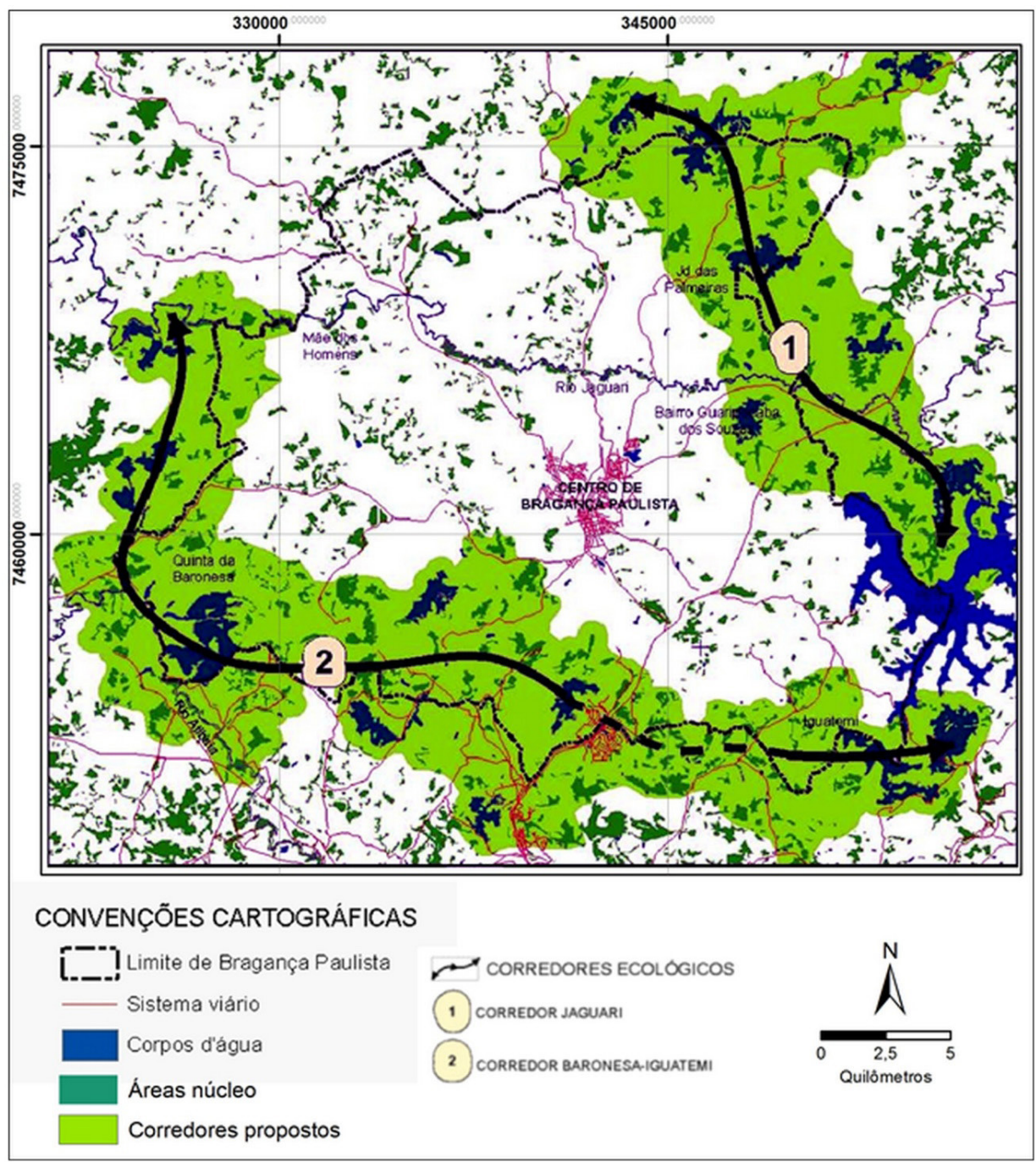

FIGURA 4: Corredores Ecológicos no município de Bragança Paulista.

FIGURE 4: Ecological corridor in the Bragança Paulista municipality.

\section{CONCLUSÃO}

Os métodos adotados para análise da paisagem apresentaram vantagens ao utilizarem métricas simples, concisas, de fácil compreensão e rápida aplicação, demonstrando-se eficiência e eficácia nos estudos voltados à observação dos fragmentos florestais nativos remanescentes de Bragança Paulista.

Os resultados obtidos indicam que há um predomínio de fragmentos pequenos. A grande maioria dos fragmentos encontrados apresentam forma alongada ou irregular e tem grande influência do efeito de borda, o que pode indicar uma baixa qualidade ambiental. A grande fragmentação observada na área de estudo pode estar relacionada à expansão do mercado imobiliário na região e, por isso, medidas mitigatórias devem ser adotadas para a melhoria dos remanescentes da região. 
Desta forma, este diagnóstico revela uma perceptível escassez de remanescentes de Mata Atlântica na região, especialmente em áreas de mananciais hídricos situados próximos ao corredor ecológico da Mantiqueira e ao mosaico de unidades de conservação da Cantareira. A proposta deste estudo permite identificar o potencial para implantação de um cinturão verde no município de Bragança Paulista, formado pelos corredores Jaguari e Baronesa-Iguatemi. A regeneração de florestas naturais deve ser estimulada, para a manutenção da biodiversidade local, ampliação dos remanescentes florestais e manutenção de APP. Este tipo de análise permite a seleção de área para a recomposição da vegetação, que permitirá a aproximação dos fragmentos e melhorar a estrutura da paisagem.

A integridade ambiental das florestas nativas de Bragança Paulista é considerada crítica e requer medidas de comando e controle por parte das instituições públicas responsáveis para conter o desmatamento ilegal da cobertura florestal. Requer também a definição de estratégias e políticas públicas para promover a recuperação ambiental através de projetos de recomposição florestal.

Sugere-se ainda estudos complementares utilizando imagens de melhor resolução espacial, em função da predominância de pequenos fragmentos na área de estudo. Esta prática permitirá uma avaliação mais precisa desses fragmentos remanescentes e, por consequência, uma melhor avaliação de suas funções na ecologia da paisagem.

\section{REFERÊNCIAS}

ALMEIDA, C. G. Análise espacial dos fragmentos florestais na área do Parque Nacional dos Campos Gerais, Paraná. 2008. 72 f. Dissertação (Mestrado em Gestão do Território) - Universidade Estadual de Ponta Grossa, Ponta Grossa, 2008.

BENNETT, A. F. Linkages in the Landscape: the role of corridors and connectivity in wildlife conservation. 2. ed. Gland; Cambridge: IUCN, 2003. v. 14.

BENNETT, A. F.; SAUNDERS, D. A. Habitat fragmentation and landscape change. Conservation Biology for All, [s. 1.], v. 93, p. 1544-1550, 2010.

BRASIL, Novo Código Florestal. Lei n 12.651, de 25 de maio de 2012. Diário Oficial [da] República Federativa do Brasil, Poder Executivo, Brasília, DF, 28 maio 2012. Seção 1, p. 1-8.

CALEGARI, L. et al. Análise da Dinâmica de Fragmentos Florestais no Município de Carandaí, MG, para Fins de Restauração Florestal. Revista Árvore, Viçosa, MG, v. 34, n. 5, p. 871-880, 2010.

CERQUEIRA, R. et al. Fragmentação: alguns conceitos. Fragmentação de ecossistemas: causas, efeitos sobre a biodiversidade e recomendações de políticas públicas. Brasília: MMA; SBF, 2003. p. 23-40.

CHATURVEDI, M. D. Measurements of the Cubical Contents of Forest Crops: being a critical investigation into the methods of measuring sample plots, with special reference to the liability to error. Oxford: Oxford University Press, 1926.

CHRISTIE, M. R.; KNOWLES, L. L. Habitat Corridors facilitate genetic resilience irrespective of species dispersal abilities or population size. Evolutionary Applications, [s. 1.], v. 8, p. 454-463, 2015.

DITT, E. H. Fragmentos florestais no Pontal do Paranapanema. São Paulo: Annablume; IPE; IIEB, 2002. $140 \mathrm{p}$.

DURIGAN, G. Protocolo de avaliação de áreas prioritárias para a conservação da Mata Atlântica na região da Serra do Mar/Paranapiacacuíba. Revista do Instituto Florestal, São Paulo, v. 21, n. 1, p. 39-54, 2009.

ENVIRONMENTAL SYSTEMS RESEARCH INSTITUTE. ArcGIS Desktop: Release 9.3. Redlands: Envrionmental Systems Research Institute, 2009.

FAHRIG, L. Effects of habitat fragmentation on biodiversity. Annual review of ecology, evolution, and systematics, [s. 1.], p. 487-515, 2003.

FUNDAÇÃO SOS MATA ATLÂNTICA; INSTITUTO NACIONAL DE PESQUISAS ESPACIAIS. Atlas dos remanescentes florestais da Mata Atlântica período de 2008-2010. São Paulo: INPE, 2011. GAMEIRO, M. S.; SUGUIO, K. Problemas geoambientais provocados pela expansão urbana no município de Bragança Paulista, SP. Revista Geociências-UnG, Guarulhos, v. 7, n. 1, p. 48-63, 2008.

GREGGIO, T. C.; PISSARRA, T. C. T.; RODRIGUES, F. M. Avaliação dos fragmentos florestais do Município de Jaboticabal-SP. Revista Árvore, Viçosa, MG, v. 33, n. 1, p. 117-124, 2009.

HADDAD, N. M. et al. Habitat fragmentation and its lasting impact on Earth's Ecosystems. 
Science Advances, Washington, v. 1, p. 1-9, 2015.

IBGE. Informações sobre os municípios brasileiros. 2015. Disponível em: <www.ibge.gov.br/cidadesat/ tpowindow.html>. Acesso em: 27 nov. 2015.

INSTITUTO FLORESTAL (SP). Inventário Florestal da Cobertura Vegetal Nativa do Estado de São Paulo do Instituto Florestal. São Paulo: IF; SMA, 2009.

KRONKA, F. J. N et al. Inventário florestal da vegetação do Estado de São Paulo. São Paulo: Secretaria do Meio Ambiente; Instituto Florestal, 2005. 200 p.

LOCH, C. et al. Definição de áreas para a formação de corredores ecológicos através da integração de dados em um Sistema de informação geográfica. Revista Brasileira de Cartografia, Rio de Janeiro, v. 3, n. 65, p. 455-465, 2013.

MAC ARTHUR, R. H.; WILSON, E. O. The theory of island biogeography. Princeton: Princeton University Press, 1967. 224 p.

MCGARIGAL, K. Landscape pattern metrics. Encyclopedia of environmetrics. England: John Wiley \& Sons, 2002.

METZGER, J. P. et al. Uso de índices de paisagem para a definição de ações de conservação e restauração da biodiversidade do Estado de São Paulo. Diretrizes para Conservação e Restauração da Biodiversidade no Estado de São Paulo. São Paulo: Secretaria do Meio Ambiente; Fapesp, 2008.

OLIVEIRA, A. M. S. (Coord.). Diagnóstico ambiental para o manejo sustentável do Núcleo Cabuçu do Parque Estadual da Cantareira e áreas vizinhas do município de Guarulhos. Projeto Cabuçu UnG/ FAPESP, Relatório Final. Guarulhos: Universidade Guarulhos, 2005.

PONÇANO, W. L. et al. Mapa geomorfológico do Estado de São Paulo: mapas. São Paulo: IPT, 1981. $94 \mathrm{p}$.

RAMBALDI, D. M.; OLIVEIRA, D. A. S. Fragmentação de ecossistemas: causas, efeitos sobre a biodiversidade e recomendações de políticas públicas. [s. 1.]: Secretaria de Biodiversidade e Florestas, 2003. $510 \mathrm{p}$.

RANTA, P. et al. The fragmented Atlantic rain forest of Brazil: size, shape and distribution of forest fragments. Biodiversity \& Conservation, London, v. 7, n. 3, p. 385-403, 1998.

RESERVA DA BIOSFERA DA MATA ATLÂNTICA (Brasil). Revisão e atualização dos limites e zoneamento da Reserva da Biosfera da Mata Atlântica em base cartográfica digitalizada: fase VI. São Paulo: Conselho Nacional da Reserva da Biosfera da Mata Atlântica, 2009.

RIBEIRO, M. C. et al. The brazilian atlantic forest: how much is left, and how is the remaining forest distributed? Implications for conservation. Biological Conservation, Essex, v. 142, p. 1141-1153, 2009.

SÃO PAULO. Centro de Pesquisas Meteorológicas e Climáticas Aplicadas a Agricultura. Clima dos Municípios Paulistas. 2009. Disponível em: <http://www.cpa.unicamp.br/outras-informacoes/ clima_muni_087.html. Acesso em: 20 nov. 2009

SOUZ̄A, C. G. et al. Análise da fragmentação florestal da área de proteção ambiental Coqueiral, Coqueiral - MG. Ciência Florestal, Santa Maria, v. 24, n. 3, p. 631-644, jul./set. 2014.

WANG, X.; BLANCHET, F.; KOPER, N. Measuring habitat fragmentation: an evaluation of landscape pattern metrics. Methods in Ecology and Evolution, [s. 1.], v. 5, n. 7, p. 634-646, 2014.

ZANELLA, L. et al. Atlantic Forest fragmentation analysis and landscape restoration management scenarios. Natureza \& Conservação, Curitiba, v. 10, n. 1, p. 57-63, 2012. 